\title{
Ultrasonic Preparation of PN For The Photodegradation of 17ß-Estradiol In Water And Biotoxicity Assessment Of E2 After Degradation
}

\author{
Kun Meng \\ Xiamen University \\ Ke-Fu Zhou \\ Xiamen University \\ Nhat-Thien Nguyen \\ National Taipei University of Technology \\ Bor-Yann Chen \\ National I-Lan University \\ Min Long \\ National I-Lan University \\ Yang-Yang Zhang \\ National I-Lan University \\ Thuy-Trang Le \\ Duy Tan University: Dai Hoc Duy Tan \\ Chang Tang Chang ( $\nabla$ ctchang@niu.edu.tw) \\ National I-Lan University https://orcid.org/0000-0003-0191-0543
}

\section{Research}

Keywords: PN-oxide hybrid, photocatalysis, 17ß-estradiol removal, zebrafish embryos

Posted Date: September 2nd, 2021

DOI: https://doi.org/10.21203/rs.3.rs-832421/v1

License: (1) (1) This work is licensed under a Creative Commons Attribution 4.0 International License. Read Full License 


\section{Abstract}

This study prepared a novel Phosphorene (PN) and load it onto $\mathrm{TiO}_{2}$ to fabricated $\mathrm{PN}-\mathrm{TiO}_{2}$, to effectively photo degrade the hydrophobic environmental hormone 17ß-estradiol in aqueous solutions. First, the corresponding characterization of prepared materials was implemented by myriads of methods (e.g, atomic force microscopy), transmission electron microscopy, scanning electron microscopy, energy dispersive spectrometer, X-ray diffraction and Raman spectroscopy. Next, the effect of the PN on the degradation efficiency was systematically investigated. Apparently, the doping of $\mathrm{TiO}_{2}$ by $\mathrm{PN}$ significantly enhanced its photocatalytic and adsorption properties with the addition of $\mathrm{PN}$, compared to that in the absence of $\mathrm{TiO}_{2}$. That is the addition improved the adsorption capability of the composite. The optimal PN weight content was found to be $0.5 \%$. However, the photo degradation efficiency gradually decreased when the PN content increased further. This optimal PN content directly suggested synergistic interactions upon the photo degrading efficiency. Compare to other PN-based photocatalysts mentioned in literature, this PN-based material owned striking advantages, such as higher energy efficiency, greater remove capacity, and superior cost-effectiveness. Further, biotoxicity of the water after treatment decreased was evident by observing the development of zebrafish embryos. In conclusion, the prepared PN-based materials exhibited promising photocatalytic capabilities for removal and biotoxicity reduction of $17 ß$-estradiol in aqueous solutions.

\section{Introduction}

For decades, Environmental Hormones (EHs) have been extensively used to augment agricultural production for exponentially-growing population need. However, although these hormones provide some benefits, they inevitably pose a serious threat to human and wildlife health. In fact, some studies have suggested that EHs have a negative impact on the reproductive system, nervous system, and the immune system of organisms, leading to slow and malformed development, decreased sperm counts, poor sperm motility, and increased cancer risks [1, 2].

Regarding environmental hormones, $17 ß$-estradiol (E2) is a typical steroid estrogen, significantly the reproduction of aquatic organisms even at extremely low concentrations. Biegel et al. [3] reported, the stripes of male crocodiles transformed to that of female crocodiles, and they exhibited female-like reproductive behavior as well due to this estrogen. The study of Diamante [4] also observed that the zebrafish embryo underwent some changes including curved body axis, yolk-sac edema, and pericardial edema after treatment with E2. Angus et al. [5] reported that high dosage of E2 led to the death of juvenile fishes in water bodies. Consequently, considerable attention has been paid towards the development of techniques for removal of E2. Including biodegradation [6-8], ion exchange [9, 10] adsorption [11, 12], and photocatalysis $[13,14]$.

Although biodegradation could facilitate the decomposition of E2 into inorganic matter to some extent, the applications of the biodegradation were still limited due to the long the long time of degradation and 
the strict conditions for bacterial growth. On the contrary, ion exchange and adsorption technologies were also incapable to degrade E2.

Compared to these methods, photocatalysis is popularly regarded as most appropriate for E2 due to its high removal efficiency, shorter degradation period, and decomposable intermediates. In the photoreaction process, light irradiates the semiconductor, to cause the excitation of electrons from the Valence Band (VB) to the Conduction Band (CB), creating positively charged holes $\left(\mathrm{h}^{+}\right)$and negatively charged electrons $\left(\mathrm{e}^{-}\right)$available for photochemistry. This process also accelerated the photocatalysis process, where a catalyst promoted secondary photoreactions due to the formation of strong oxidizing capabilities of holes and reducing potentials of electrons [15].

Among the typical catalysts (e.g, $\left.\mathrm{TiO}_{2}, \mathrm{CeO}_{2}, \mathrm{ZnO}, \mathrm{SnO}_{2}\right), \mathrm{TiO}_{2}$ is widely used in the photocatalysis process as it is a chemically stable, low cost, and nontoxic material with promising reusability [16]. Recently, significant attention has been paid towards heterogeneous doping of $\mathrm{TiO}_{2}$ to enhance adsorption under visible light irradiation by decreasing its band gap, and preventing the recombination of electrons and holes. However, several investigations utilized expensive heavy metals (e.g. Au, Ag, and Pt) as dopant $[17,18]$ to increase the overall cost and the pollution risk. Consequently, an environmentally friendly and biocompatible substitute, $\mathrm{PN}-\mathrm{TiO}_{2}$, has been proposed for the photo decomposition of E2.

Regarding novel materials, Phosphorene (PN) is a novel Two-Dimensional (2D) material with a high current on/off ratio $\left(\sim 10^{4}-10^{5}\right)$ and high electron mobility $\left(\sim 200-1000 \mathrm{~cm}^{2} \mathrm{~V}^{-1} \mathrm{~s}^{-1}\right)$ at room temperature [19-21]. Therefore, it can be used to dope $\mathrm{TiO}_{2}$, to enhance the excitation of electrons from $V B$ to $C B$ and inhibit electron-hole recombination, leading to the increased generation of hydroxyl radicals $(\cdot \mathrm{OH})$. Furthermore, Wang et al. [22] have reported that $\cdot \mathrm{OH}$ and ${ }^{1} \mathrm{O}_{2}$ could be generated when $\mathrm{PN}$ is irradiated with Ultraviolet (UV) and visible light, respectively. This strongly supported that PN is an electrochemically feasible photocatalyst. Therefore, photocatalytic performance of $\mathrm{TiO}_{2}$ may be improved if it is doped with PN. In addition, PN owns a large specific surface area [23] that aids the adsorption of contaminants onto the reactive sites at the surface of $\mathrm{TiO}_{2}$, significantly promoting the removal of E2.

In this study, PN was fabricated to mix with various amounts $(0.5 \%, 1.0 \%$ and $3.0 \%$ weight) of PN and $\mathrm{TiO}_{2}$ using microwave heating to synthesize $\mathrm{PN}-\mathrm{TiO}_{2}$ composites, (e.g, $0.5 \% \mathrm{PN}-\mathrm{TiO}_{2}, 1.0 \% \mathrm{PN}-\mathrm{TiO}_{2}$, and $3.0 \% \mathrm{PN}-\mathrm{TiO}_{2}$ ). The degradation efficiencies of these composites are investigated to quantify the performance of E2 elimination. Although several studies [24-26] investigated the degradation efficiency of $\mathrm{TiO}_{2}$ or $\mathrm{TiO}_{2}$-based composites, the removal capacities were still low and the operation inevitably required strong illumination. In this study, only an 8 W UV light source was used to demonstrate treatability of effective photocatalysis with cost and energy-effectiveness. This study exhibited the most representative PN-based hybrid for elimination of hydrophobic and refractory pollutants in aqueous solutions. 


\section{Materials And Methods \\ 2.1. Chemical reagents}

Bulk Black Phosphorus (BP) was obtained from XFNANO materials tech limited company. Model pollutant $17 ß$-estradiol $\left(E_{2}\right.$, purity $\geq 98 \%$ ) was purchased from Sigma Nano- $\mathrm{TiO}_{2}$ provided from ACROS company. Ultrapure hydroelectricity was prepared using the OTUN ultrapure water system (OR007XXM1, ELGA). Stock solutions of the $E_{2}$ were prepared by dissolving ca. $0.1 \mathrm{mg}$ of the $E_{2}$ in $100 \mathrm{~mL}$ of methanol, well stirring for $5 \mathrm{~min}$. The solution was then maintained at $4{ }^{\circ} \mathrm{C}$ for further use.

\subsection{Preparation of Phosphorene Nanosheets (PN) and Phosphorene - $\mathrm{TiO}_{2}$ composites $\left(\mathrm{PN}-\mathrm{TiO}_{2}\right)$}

PN was prepared by exfoliating the bulk BP in liquid by ultrasonic treatment. Sequentially, $25 \mathrm{mg}$ of bulk sample was dispersed into $50 \mathrm{~mL}$ ethanol (purity $\geq 99.5 \%$ ) followed by purging $\mathrm{N}_{2}$ to remove residual dissolved oxygen (i.e. crucial step preventing PN oxidation). Then, the mixture was place in ice water for $12 \mathrm{~h}$ sonication. Finally, the brown suspension was centrifuged at $3000 \mathrm{rpm}$ for $10 \mathrm{~min}$ to harvest the supernatant. Then, the solution was bubbled with $\mathrm{N}_{2}$ for 5 min and then maintained in $4{ }^{\circ} \mathrm{C}$ for preparation of $\mathrm{PN}-\mathrm{TiO}_{2}$. The supernatant was then dried at $60^{\circ} \mathrm{C}$ for approximately $8 \mathrm{~h}$ to obtain $\mathrm{PN}$ powder. Hereafter, the $\mathrm{PN}$ content at $0.5 \%, 1.0 \%$, and $3.0 \%$ were used to mix with $\mathrm{TiO}_{2}$, followed by adding into $15 \mathrm{~mL}$ DI water. Then, the solutions were well stirred under ultrasonication for $1 \mathrm{~h}$ and then micro waved $\left(200{ }^{\circ} \mathrm{C}, 400 \mathrm{~W}\right)$ for $30 \mathrm{~min}$. Finally, the mixtures were dried at $60^{\circ} \mathrm{C}$ to harvest $\mathrm{PN}-\mathrm{TiO}_{2}$ composites (denoted as $0.5 \% \mathrm{PN}-\mathrm{TiO}_{2}, 1.0 \% \mathrm{PN}-\mathrm{TiO}_{2}$ and $3.0 \% \mathrm{PN}-\mathrm{TiO}_{2}$, respectively). The characterization of $\mathrm{PN}$ and $\mathrm{PN}-\mathrm{TiO}_{2}$ were then implemented via Transmission Electron Microscope (TEM), Atomic Force Microscope (AFM), Raman spectroscopy, X-ray Diffraction (XRD), UV-Vis spectrophotometer (UV-Vis), Field Emission Scanning Electron Microscope (FE-SEM), Energy Dispersive Spectrometer (EDS) and elemental maps.

\subsection{Photodegradation reaction}

The cylindrical reactor ( $7 \mathrm{~cm}$ diameter and $40 \mathrm{~cm}$ height) was used for the treatability study of photocatalytic degradation. In addition, an 8 W UV lamp $\left(0.55 \mathrm{~mW} \mathrm{~cm}^{-2}\right)$ as source of minimum energy supply was equipped to provide sufficient energy to trigger photodegradation process to be taken place. Subsequently, $0.05 \mathrm{~g}$ of $\mathrm{PN}^{-\mathrm{TiO}_{2}}$ was supplemented into $500 \mathrm{~mL}$ of $10 \mathrm{ppm}$ E2 diluted in $2 \%$ methanol diluted with deionized water. The reaction was first conducted in dark for $30 \mathrm{~min}$ to achieve equilibrium for absorption and then UV light was switched on to trigger photocatalysis. All the experiments were conducted at inherent solution pH and $30 \pm 0.2^{\circ} \mathrm{C}$ at $300 \mathrm{rpm}$. The samples were then conducted (without removing photocatalysts) using a millipore filter with pore size of $0.22 \mu \mathrm{m}$. E2 concentration of samples was analyzed through high performance liquid chromatography. The flow phase was a solution mixture of ultrapure water and acetonitrile in $48: 52$ volumetric ratios eluting the pollutant with $1.2 \mathrm{~mL} \mathrm{~min}^{-1}$ of 
flow rate. In addition to $20 \mu \mathrm{L}$ of injection volume and $25^{\circ} \mathrm{C}$ of column, the retention time was set to 5.5 min for E2.

\section{Results And Discussion}

\subsection{Material characterization}

To confirm the formation of composites through sample characterization, as TEM, FE-SEM, XRD, Raman, UV-Vis and EDS analyses were performed. The surface morphology of the crystalline composites could be easily observed from TEM images as indicated in Fig. 1. Figure 1(a) clearly exhibited the ultrathin film structure of the samples confirmed to be characterization of 2D material as revealed. Moreover, electron diffraction patterns of selected area as shown in Fig. 1(b) also confirmed the crystalline nature of the sample. To further determine the thickness of PN, AFM characterization technique was applied through optical contrast analysis (Fig. 2(a)). The results indicated that clear edges of PN were still sharpened, suggesting that oxidation was unlikely implemented during material preparation. Moreover, the height profile from Fig. 2(b) displayed the thickness of PN was ca. 3.0-5.0 nm. According to Liu et al. [27], the thickness of single layer PN was approximately $0.9 \mathrm{~nm}$, suggesting that the number of the sample layer could be ca. 3-5. This was consistent with the finding from TEM.

To identify the substructure and electronic feature of $\mathrm{PN}$ and $\mathrm{PN}-\mathrm{TiO}_{2}$ composite, Raman spectra was implemented Fig. 3. The results indicated that three Raman characteristic peaks of black BP and PN were displayed nearly at $361 \mathrm{~cm}^{-1}, 436 \mathrm{~cm}^{-1}$ and $463 \mathrm{~cm}^{-1}$. These peak wavelengths corresponded to phosphorous. It was confirmed that the second sample prepared was indeed phosphorous homologous substance. An apparent shift was observed for the composite samples at $361 \mathrm{~cm}^{-1}$ and $463 \mathrm{~cm}^{-1}$, indicating comparatively the smaller thickness than that of BP. This was due to a positive relationship between the extent of shift and PN thickness as reported in literature [27]. There were more and less obvious additional peaks at $144 \mathrm{~cm}^{-1} 391 \mathrm{~cm}^{-1}$ respectively in Raman spectroscopy of $\mathrm{PN}^{-\mathrm{TiO}_{2}}$. The two characteristic peaks were corresponding to the typical figure of Raman spectra for anatase, directly indicating that $\mathrm{TiO}_{2}$ sample was P25 and the ratio of anatase to rutile was at 80/20 [28]. Moreover, the formation of three signal nearly identified location at $361 \mathrm{~cm}^{-1}, 436 \mathrm{~cm}^{-1}$ and $463 \mathrm{~cm}^{-1}$, in the curve of PN$\mathrm{TiO}_{2}$ composites, suggesting that $\mathrm{PN}$ was successfully combined with $\mathrm{TiO}_{2}[29]$.

In addition, XRD patterns of the samples were obtained to reveal the crystalline structure and phase purity of $\mathrm{PN}$ and $\mathrm{PN}-\mathrm{TiO}_{2}$ composites (Fig. 4). As Fig. 4(a) revealed, PN exhibited the apparent peaks for ( $\left.h k l\right)$ 020,040 planes, according to JCPDS card No. 47-1626. The $d$ spacing between the $h k /$ planes has been calculated on account of the reported values of bulk BP [30], suggesting the content of sample was possibly the element $P$. Both results of TEM and AFM confirmed that PN was prepared successfully. With respect to the XRD image of $\mathrm{PN}-\mathrm{TiO}_{2}$ composites (Fig. 4(b)), all relatively high characteristic peaks were reflected to the JCPDS card No.21-1272, for anatase. It was consisted with the fact that $\mathrm{TiO}_{2}$ used in this 
study was P25, anatase approximately at $80 \%$. Due to the absence of characteristic peaks of other impurities, this simply suggested the high purity of the composites for study.

To observe the changes on the absorption spectra of these four composites with different PN content at $0.5 \% \mathrm{PN}-\mathrm{TiO}_{2}, 1.0 \% \mathrm{PN}-\mathrm{TiO}_{2}$ and $3.0 \% \mathrm{PN}-\mathrm{TiO}_{2}$. UV-Vis analysis was carried out at the range between 200 $\mathrm{nm}$ to $800 \mathrm{~nm}$. As indicated in Fig. 5, the results directly pointed out that gradually increased capacity of adsorption within visible light ranges were shown with increased PN content. Although there was a slight decrease in the adsorption value within UV light, the Eg value of these composites determined by Eq. (1) was still lower, and the order of decreasing in the adsorption was as follows; $\mathrm{Eg}_{3.0 \% \mathrm{PN}-\mathrm{TiO} 2}(2.6 \mathrm{eV})<$

$\mathrm{Eg}_{1.0 \% \mathrm{PN}-\mathrm{TiO} 2}(2.8 \mathrm{eV}) \approx \mathrm{Eg}_{0.5 \% \mathrm{PN}-\mathrm{TTO} 2}(2.8 \mathrm{eV})<\mathrm{Eg}_{\mathrm{TiO} 2}(3.0 \mathrm{eV})$.

$E g=\frac{1240}{\lambda}$

Where, parameter $\lambda$ is the node value of tangent of spectra and $X$ axis.

To explore characterization of material preparation, the surface morphology of $\mathrm{PN}-\mathrm{TiO}_{2}$ was also studied via FE-SEM (Fig. 6(a)). As FE-SEM image indicated, the particle of $\mathrm{TiO}_{2}$ was evenly distributed with nearly no particle aggregation. Figure 6(b), showed a typical EDS image of $\mathrm{PN}-\mathrm{TiO}_{2}$ composite. The EDS image uncovered that the composite consisted of $\mathrm{P}, \mathrm{Ti}$ and $\mathrm{O}$ elements. Combining the results obtained from both Fig. 6(c) and elemental maps of $\mathrm{PN}-\mathrm{TiO}_{2}$, the three elements were completely mixed and $\mathrm{P}$ was successfully loaded onto $\mathrm{TiO}_{2}$ (Fig. 6(d)).

\subsection{Photodegradation performance of $\mathrm{PN}-\mathrm{TiO}_{2}$}

\subsubsection{Effect of different contents of PN}

This study was investigated the photocatalytic efficiency of composites with different PN contents. 0.05 $\mathrm{g}$ of $\mathrm{TiO}_{2}, 0.5 \% \mathrm{PN}-\mathrm{TiO}_{2}, 1.0 \% \mathrm{PN}-\mathrm{TiO}_{2}$ and $3.0 \% \mathrm{PN}-\mathrm{TiO}_{2}$ were individually mixed with $500 \mathrm{ml}$ of $10 \mathrm{ppm} \mathrm{E2}$ solution for comparative study. As Fig. 7 indicated, the removal of E2 is significantly improved with an increase in PN content. In addition, bare $\mathrm{TiO}_{2}$ was observed to be more hydrophilic, leading to less adsorption of E2 on the surface of the catalyst. However, it may be observed that the photodegradation of E2 is enhanced for $0.5 \% \mathrm{PN}$, but further increase in the PN content would decrease the degradation performance. This may be attributed to the fact that PN as an electron acceptor could prevent electronhole recombination caused by $\mathrm{TiO}_{2}[31-34]$. Moreover, $\mathrm{h}^{+}$could react with water and oxygen to generate $\cdot \mathrm{OH}$ to eliminate $\mathrm{E} 2$, as shown in equation $\mathrm{B}(2)-\mathrm{B}(6)$. On the other hand, $\cdot \mathrm{OH}$ can also be generated due to the excitation of PN by UV light [22]. Thus, increased photodegradation efficiency would be shown when $\mathrm{PN}$ was doped into $\mathrm{TiO}_{2}$. However, the excessive PN content still affected the absorption of the catalyst, leading to a decreased catalytic activity. This was confirmed by the UV-Vis absorption spectra of $\mathrm{PN}-\mathrm{TiO}_{2}$ (in Fig. 5). Furthermore, it was also observed that PN could be significantly accumulated when its content was very high; therefore, it could not prevent the electron-hole recombination. Consequently, the catalytic activity of $\mathrm{PN}-\mathrm{TiO}_{2}$ composite would be attenuated [35]. 
$h v+\mathrm{TiO}_{2} \rightarrow e^{-}+h^{+}(2)$

$h^{+}+\mathrm{H}_{2} \mathrm{O}+\mathrm{O}_{2} \rightarrow \cdot \mathrm{OH}+\mathrm{O}_{2}^{-}$

$\mathrm{O}_{2}^{-}+\mathrm{HO}_{2}+\mathrm{H}^{+} \rightarrow \mathrm{H}_{2} \mathrm{O}_{2}+\mathrm{O}_{2}$

$e^{-}+\mathrm{H}_{2} \mathrm{O}_{2} \rightarrow \mathrm{OH}^{-}+\cdot \mathrm{OH}(5)$

$h^{+} / O H+E 2 \rightarrow$ byproducts $(6)$

\subsubsection{The biotoxicity of the water after degradation}

To evaluate the biotoxicity of the treated water, zebrafish was used as the model organism. Ten in each group were exposed into the clean water (group 1), the wastewater containing E2 (group 2) and the treated water (group 3), respectively. The hatching rate, mortality rate and heart rate were observed to investigate the effect of water before and after degradation on the development of zebrafish embryos. Then, it can be understood whether the photocatalysis degradation system is effective.

Figure 8 shows heart rate increased with the development of the embryos in a natural environment (group 1), which was in contrast to that in the water containing E2 (group 2 and group 3). The heart rate in group 3 was slightly higher in the beginning and then decreased with the time accumulation. It indicated that a certain concentration of E2 may lead some response in a short time, however, the biotoxicity effect emerged afterward, which was the reason that the heart rate in group 3 decreased at 48-96 h. Besides, a significant decrease was observed in group 2, demonstrating that the higher concentration of E2 has a negative effect on the metabolic activity of zebrafish embryos and inhibits their growth. Those results are corresponded with Ulhaq and KishidaM [36]. What's more, the difference between group 2 and group 3 shows that the photocatalysis degradation decreased the activity of E2 and its biotoxicity.

According to Fig. 8, zebrafish eggs started to hatch out from the second day and the highest hatching rate appeared on the third day. However, there was a significant difference between the hatching rate of the group 2 and the other two groups. Furthermore, the hatching rate in group 2 was significantly lower in the whole hatching process, which demonstrated that a higher concentration of E2 will inhibit the development of zebrafish embryos, leading the lower hatching rate meanwhile, which is consistent with the report of Lee et al. [37]. And there was no significant difference between group1 and group3, indicating that the water environment in the two groups was similar.

From Fig. 8, the mortality rate of embryos was getting higher in 3 groups with time accumulating, while the rate was the highest in group 2. It can be inferred that higher E2 concentration may lead higher mortality of zebrafish embryos. In study of Ren et al. [38] also mentioned that higher level E2 $(>10 \mu \mathrm{M})$ would lead zebrafish malformation or mortality. Also, it can be observed that the mortality rate of zebrafish embryos in group 3 was significantly lower than that in group 2 and similar to the group 1 , suggesting that the water after degradation will lead a lower mortality rate of zebrafish embryos. In 
conclusion, the photocatalysis system was effective for the degradation of E2 and can decrease its negative effect on the development of zebrafish embryos.

\subsection{Comparative assessment of degradation performance}

To compare degradation efficiency of other materials, degradation performances of similar materials obtained from literature were adopted (Table 2). Evidently this study indicated that the removal rate and photocatalytic capacity are promising in our study. The efficiency for the removal of $10 \mathrm{ppm}$ E2 solution could achieve $79.5 \%$ within $3 \mathrm{~h}$, which was much more than that reported data $[13,14]$. For example, the removal capacity is $39.8 \mathrm{mg} \mathrm{g}^{-1}$. Alvarez-Corena et al. [35] reported that the degradation efficiency was significantly enhanced when $\mathrm{O}_{2}$ was added to pure $\mathrm{TiO}_{2}$ for E2-containing wastewater treatment. In addition, the degradation rate was $0.53 \mathrm{~min}^{-1}, 5-10$ times higher than that reported in other studies. However, $\mathrm{O}_{2}$ was required to be supplied continuously during this process, inevitably leading to a higher cost for practical applications. Li et al. [31] and Fernandez et al. [32] reported a degradation efficiency of 99.5\% and $90 \%$ when $\mathrm{Fe}_{-} \mathrm{Bi}_{2} \mathrm{SiO}_{5}$ and $\mathrm{P} 25$ were utilized to decompose $\mathrm{E} 2$ at $3 \mathrm{ppm}$ and $1 \mathrm{ppm}$ in aqueous solution, respectively. According to Langmuir-Hinshelwood mechanism, these higher efficiencies were likely attributed to the lower E2 concentration. Consequently, their removal capacities were approximately $5.97 \mathrm{mg} \mathrm{g}^{-1}$ and $1.80 \mathrm{mg} \mathrm{g}^{-1}$, around $1 / 8$ and $1 / 20$ times lower than that in our study, respectively. Moreover, a high intensity UV lamp was still required to be used in these two studies and costeffectiveness problems were still of great concern. In fact, Yang et al. [26] used a 20 W UV lamp in their study. FTG (surface fluorinated $\mathrm{TiO}_{2} /$ reduced graphene oxide) and $\mathrm{TiO}_{2}-\mathrm{RGO}$ (reduced graphene oxide) were prepared to remove 3 ppm E2 solution even the degradation efficiency could reach up to $99.8 \%$ and $83.3 \%$ in $180 \mathrm{~min}$, respectively. These were higher than the efficiencies of P25 (74.4\%) and our study (79.5\%). In particular, FTG was capable to completely remove 3 ppm E2 in wastewater in $3 \mathrm{~h}$. This was possibly due to the vital role of $\mathrm{F}$ - in photocatalysis. The adsorption of $\mathrm{F}$ - on the surface of $\mathrm{TiO}_{2}$ improved the crystallization of the $\mathrm{TiO}_{2}$ anatase phase. However, the $\cdot \mathrm{OH}$ radicals generated on the surface of $\mathrm{F}$ $\mathrm{TiO}_{2}$ were more mobile than those generated on pure $\mathrm{TiO}_{2}$ under $\mathrm{UV}$ irradiation [33]. Further, $\mathrm{F}$ - is harmful for the environment and ecosystem, implying that a secondary pollutant could be generated without recycles. Furthermore, a UV lamp of higher intensity was used here, and the removal capacity was still much lower than our study. 
Table 1

Comparison of degradation efficiency and removal capacity of this study with literature

\begin{tabular}{|c|c|c|c|c|c|c|}
\hline Reference & Materials & $\begin{array}{l}\mathrm{C}_{0}\left(\mathrm{~L}^{-}\right. \\
1)\end{array}$ & $\begin{array}{l}\text { Degradation } \\
\text { efficiency }\end{array}$ & Light source & $\begin{array}{l}\mathrm{K}_{1} \\
\left(\mathrm{~min}^{-}\right. \\
\left.{ }^{-}\right)\end{array}$ & $\begin{array}{l}\text { Removal } \\
\text { capacity } \\
\left(\mathrm{mg} \mathrm{g}^{-1}\right)\end{array}$ \\
\hline [23] & $\begin{array}{l}\text { Immobilized } \\
\mathrm{TiO}_{2}\end{array}$ & $\begin{array}{l}44.0 \\
\mu \mathrm{g}\end{array}$ & $45 \%(180 \mathrm{~min})$ & 36 W UV & 0.003 & 0.013 \\
\hline [36] & $\mathrm{TiO}_{2}+\mathrm{O}_{2}$ & $\begin{array}{l}2.0 \\
\mathrm{mg}\end{array}$ & $93 \%$ (25 min) & 100 W UV & 0.53 & 18.6 \\
\hline [14] & $\mathrm{TiO}_{2}-\mathrm{FeZ}$ & $\begin{array}{l}1.4 \\
\mathrm{mg}\end{array}$ & $78 \%(90 \mathrm{~min})$ & $450 \mathrm{~W} X e$ & 0.015 & 25.3 \\
\hline [25] & FTG4 & $\begin{array}{l}3.0 \\
\mathrm{mg}\end{array}$ & $99 \%$ (180 min) & 20 W UV & 0.035 & Unsaturation \\
\hline [25] & $\mathrm{TiO}_{2}-\mathrm{RGO}$ & $\begin{array}{l}3.0 \\
\mathrm{mg}\end{array}$ & 83\% (180 min) & 20 W UV & 0.010 & 8.33 \\
\hline [25] & P25 & $\begin{array}{l}3.0 \\
\mathrm{mg}\end{array}$ & $74 \%$ (180 min) & 20 W UV & 0.008 & 7.44 \\
\hline [13] & NTT & $\begin{array}{l}0.5 \\
\mathrm{mg}\end{array}$ & $65 \%(150 \mathrm{~min})$ & $\begin{array}{l}3300 \mu \mathrm{W} \mathrm{cm} \mathrm{cm}^{-} \\
2 \mathrm{UV}\end{array}$ & 0.007 & 3.51 \\
\hline [37] & $\mathrm{Fe}-\mathrm{Bi}_{2} \mathrm{SiO}_{5}$ & $\begin{array}{l}3.0 \\
\mathrm{mg}\end{array}$ & $99 \%(60 \mathrm{~min})$ & 20 W UV & 0.069 & 5.97 \\
\hline [38] & P25 & $\begin{array}{l}1.0 \\
\mathrm{mg}\end{array}$ & $90 \%(3 \mathrm{~h})$ & 64 W UV & 0.013 & 1.8 \\
\hline [24] & $4 \% \mathrm{GO}-\mathrm{TiO}_{2}$ & $\begin{array}{l}1.0 \\
\mathrm{mg}\end{array}$ & $48 \%(60 \mathrm{~min})$ & $450 \mathrm{~W} X e$ & 0.011 & 24.0 \\
\hline $\begin{array}{l}\text { This } \\
\text { study }\end{array}$ & $\mathrm{PN}-\mathrm{TiO}_{2}$ & $\begin{array}{l}10.0 \\
\mathrm{mg}\end{array}$ & $68 \%$ & 8 W UV & 0.006 & 67.5 \\
\hline
\end{tabular}


Table 2

$\mathrm{PN}$ and PN-based hybrids and their fields of application

\begin{tabular}{|lll|}
\hline Reference & Material & Filed of application \\
\hline$[26]$ & PN-GN hybrid & Perpendicular electric field \\
\hline$[27]$ & PN-GN hybrid & Schottky barrier diode \\
\hline$[28]$ & PN-MoS 2 & Electric field / solar cell \\
\hline$[29]$ & PN-h-BN & Electric field \\
\hline$[22]$ & PN & Photocatalysis for DPBF \\
\hline$[30]$ & (more)PN-TiO 2 & Photocatalysis for dye \\
\hline This study & (less)PN-TiO 2 & Photocatalysisfor 17ß-estradiol \\
\hline $\begin{array}{l}\text { Note: PN, GN, BN, and DPBF indicate phosphorene, graphene, hexagonal boron nitride, and 1,3- } \\
\text { diphenylisobenzofuran, respectively. }\end{array}$ \\
\hline
\end{tabular}

This study used $\mathrm{PN}$ and $\mathrm{PN}-\mathrm{TiO}_{2}$ composite as photocatalysts. Although the mass $\%$ of $\mathrm{PN}$ is merely $0.5 \%$ in the composite, the degradation efficiency was more significantly improved than that of bare $\mathrm{TiO}_{2}$. Furthermore, using UV lamp with very low intensity $(8 \mathrm{~W})$, suggested that this technique is not only costeffective, but also energy-efficient. This is consistent with aim of green sustainability and environment friendliness. The removal capacity of $39.8 \mathrm{mg} \mathrm{g}^{-1}$ was still much higher than that reported in literature (Table 2). However, the degradation rate still required to be further improved from kinetic perspective for overall performance consideration.

\subsection{Significance of the study}

Recently, a novel 2D material, PN, has brought considerable attention for study owing to its physical, electrical, and chemical characteristics. Most of these studies focused on the electrical applications of PN (e.g, solar cells and barrier diodes) [39,40], and rare studies investigated its photocatalytic properties (Table 2). In this study, $\mathrm{PN}$ was mixed with a commonly-used oxide $\mathrm{TiO}_{2}$ to prepare $\mathrm{PN}-\mathrm{TiO}_{2}$ hybrid. The advantages of this hybrid could be shown as follows: 1) PN exhibited synergistic interactions to photodegradation due to its inherent photocatalytic properties; 2) The proposed doping of PN (instead of expensive metals) into $\mathrm{TiO}_{2}$ was biocompatible and cost-effective; 3) $\mathrm{PN}-\mathrm{TiO}_{2}$ composites were stable to prevent the reaction of PN with water and oxygen. Lee et al. [28] reported $\mathrm{BP} @ \mathrm{TiO}_{2}$ as a promising photocatalyst for dye photodegradation. However, the mass content of PN was very high in this composite, and thus increases the overall cost, since PN is still not economically feasible as compared to $\mathrm{TiO}_{2}$. Regarding the synergistic photocatalysis, $\mathrm{PN}$ inhibits the electron-hole recombination due to its high electron mobility, improving its degradation efficiency of the hybrid for pollutant elimination. Moreover, the addition of PN increased the degradation efficiency by $30 \%$ in the aqueous phase compared to that exhibited by bare $\mathrm{TiO}_{2}$. The maximum degradation efficiency was achieved at an optimum content of PN at $1.0 \%$ wt. Therefore, the overall cost was still much lower than that reported results of Lee et al. [28]. 
This study provided a considerable prospect for the fabrication of other $\mathrm{PN}$-oxide hybrids (e.g, $\mathrm{PN}^{-\mathrm{WO}_{3}}$ and $\mathrm{PN}-\mathrm{CeO}_{2}$ ) to exhibit comparable photodegradation performance.

\section{Conclusions}

The enhanced photodegradation of 17ß-estradiol by phosphorene-basing composites was reported via successful preparation of $\mathrm{PN}$ and $\mathrm{PN}-\mathrm{TiO}_{2}$ photocatalysts through detailed characterization. The extent of degradation of E2 could reach to $79.5 \%$ with $\mathrm{PN}-\mathrm{TiO}_{2}$ under UV light within 180 min, which were almost two folds greater than that of bare $\mathrm{TiO}_{2}$. To the best of our knowledge, this was the first attempt to combine PN with other catalysts for degradation of refractory and hydrophobic pollutants (e.g., E2). During the reaction process, $\mathrm{PN}$ could adsorb E2 onto the surface of $\mathrm{TiO}_{2}$. Thus, it could facilitate the photodegradation due to the formation of $\cdot \mathrm{OH}$ radical. In addition, the combination of $\mathrm{e}^{-}$with $\mathrm{h}^{+}$could be restrained by $\mathrm{PN}$ that could also generate $\cdot \mathrm{OH}$ on collaboration with $\mathrm{TiO}_{2}$ to attack $\mathrm{E} 2$. This is the reason why the degradation efficiency and removal capacity of E2 were higher than that of bare $\mathrm{TiO}_{2}$. However, some intermediates could be possibly produced with high estrogen activity during this photodegradation process, leading to threaten to aquatic organisms and human. Therefore, in follow-up studies for the intermediate analysis and biotoxicity assessment would be carried out.

\section{Declarations}

\section{Availability of data and materials}

All data generated or analyzed during this study are examined by our group and certified for several times.

\section{Competing interests}

The authors declare they have no competing interests.

\section{Funding}

Not applicable

\section{Authors' contributions}

Kun Meng and Ke-Fu Zhou provided real test data, Nhat-Thien Nguyen analyzed the test data, Bor-Yann Chen and Min Long supported the test data, Thuy-Trang Le wrote the paper, and Chang-Tang Chang organized the researched full structure. All authors read and approved the final manuscript.

\section{Acknowledgements}

This work was supported by the National Key Research and Development Program of China (2016YFC0502901) and the National Key Research and Development Program of China 
(2017YFC0506103). The authors would like to thank the Ministry of Science and Technology of Taiwan for providing financial support for project MOST 106-2622-E-197-003-CC3.

\section{References}

1. Finn RS, Aleshin A, Slamon DJ. Targeting the cyclin-dependent kinases (CDK) $4 / 6$ in estrogen receptor-positive breast cancers. Breast Cancer Res. 2016;18(1):17.

2. Sanders JM, Coulter SJ, Knudsen GA, Dunnick JK, Kissling GE, Birnbaum LS. Disruption of estrogen homeostasis as a mechanism for uterine toxicity in Wistar Han rats treated with tetrabromobisphenol A. Toxicol appl pharmacol. 2016;298:31-39.

3. Biegel LB, Flaws JA, Hirshfield AN, O'Connor JC, Elliott GS, Ladics GS, et al. Cook, 90-day feeding and one-generation reproduction study in Crl: CD BR rats with 17ß-estradiol. Toxicol sci. 1998;44(2):116142.

4. Diamante G. Contribution of G protein-coupled estrogen receptor 1 (GPER) to $17 \beta$-estradiol-induced developmental toxicity in zebrafish. Aquat toxicol. 2017;186:180-187.

5. Angus RA, Stanko J, Jenkins RL, Watson RD. Effects of 17a-ethynylestradiol on sexual development of male western mosquitofish (Gambusia affinis). Comp Biochem Physiol C Toxicol Pharmacol. 2005;140(3-4):330-339.

6. Li M, Zhao X, Zhang X, Wu D, Leng S. Biodegradation of 17ß-estradiol by Bacterial Co-culture Isolated from Manure. Sci rep. 2018;8(1):3787.

7. Xiong W, Peng W, Liang R. Identification and genome analysis of Deinococcus actinosclerus SJTR1, a novel 17ß-estradiol degradation bacterium. 3 Biotech. 2018;8(10):433.

8. Yu Q, Wang P, Liu D, Gao R, Shao H, Zhao H, et al. Degradation characteristics and metabolic pathway of $17 \beta$-estradiol (E2) by Rhodococcus sp. DS201. Biotechnol Bioprocess Eng. 2016:21(6):804-813.

9. Mazlan WS, Mokhtar H, Hamid NSA, Tajuddin RM. Fabrication of ultrafiltration membrane using addtive to extract hormone from poultry wastewater, J Teknol. 2016;78(5-3):121-126.

10. Tong Y, McNamara PJ, Mayer BK. Fate and impacts of triclosan, sulfamethoxazole, and $17 \beta-$ estradiol during nutrient recovery via ion exchange and struvite precipitation. Environ Sci Water Res Technol. 2017;3(6):1109-1119.

11. Jiang LH, Liu YG, Zeng GM, Xiao FY, Hu XJ, Hu X, et al. Removal of $17 \beta$-estradiol by few-layered graphene oxide nanosheets from aqueous solutions: external influence and adsorption mechanism. Chem Eng J. 2016;284:93-102.

12. Jiang L, Liu Y, Liu S, Hu X, Zeng G, Hu X, et al. Fabrication of $\beta$-cyclodextrin/poly (I-glutamic acid) supported magnetic graphene oxide and its adsorption behavior for $17 \beta$-estradiol. Chem Eng J. 2017;308:597-605.

13. Kim S, Cho H, Joo H, Her N, Han J, Yi K, et al. Evaluation of performance with small and scale-up rotating and flat reactors; photocatalytic degradation of bisphenol $\mathrm{A}, 17 \beta$-estradiol, and 17a-ethynyl 
estradiol under solar irradiation. J Hazard Mater. 2017;336:21-32.

14. Kovacic M, Kopcic N, Kusic H, Bozic AL. Solar driven degradation of 17ß-estradiol using composite photocatalytic materials and artificial irradiation source: Influence of process and water matrix parameters. J Photochem Photobiol A Chem. 2018;361:48-61.

15. Saravanan R, Gracia F, Stephen A. Basic principles, mechanism, and challenges of photocatalysis. Nanocomposites for Visible Light-induced Photocatalysis. 2017;19-40.

16. Xing Z, Zhang J, Cui J, Yin J, Zhao T, Kuang J, et al. Recent advances in floating $\mathrm{TiO}_{2}$-based photocatalysts for environmental application. Appl Catalys B Environ. 2018;225:452-467.

17. Tahir K, Ahmad A, Li B, Nazir S, Khan A U, Nasir T, et al. Visible light photo catalytic inactivation of bacteria and photo degradation of methylene blue with $\mathrm{Ag} / \mathrm{TiO}_{2}$ nanocomposite prepared by a novel method. J Photochem Photobiol B Biol. 2016;162:189-198.

18. Vaiano V, lervolino G, Sannino D, Murcia JJ, Hidalgo MC, Ciambelli P, et al. Photocatalytic removal of patent blue V dye on Au- $\mathrm{TiO}_{2}$ and $\mathrm{Pt}-\mathrm{TiO}_{2}$ catalysts. Appl Catal B Environ. 2016; 188:134-146.

19. Wang H, Yang X, Shao W, Chen S, Xie J, Zhang X, et al. Ultrathin black phosphorus nanosheets for efficient singlet oxygen generation. J Am Chem Soc. 2015;137(35):11376-82.

20. Bagheri S, Mansouri N, Aghaie E. Phosphorene: A new competitor for graphene. Int J Hydrog Energy. 2016:41(7):4085-4095.

21. Khandelwal A, Mani K, Karigerasi MH, Lahiri I. Phosphorene-the two-dimensional black phosphorous: Properties, synthesis and applications. Mater Sci Eng B. 2017;221:17-34.

22. Wang $H$, Jiang $S$, Shao W,Zhang $X$, Chen $S$, Sun $X$, et al. Optically switchable photocatalysis in ultrathin black phosphorus nanosheets. J Am Chem Soc. 2018;140(9):3474-3480.

23. Hu ZT, Liu J, Yan X, Oh WD. Low-temperature synthesis of graphene/Bi2Fe409 composite for synergistic adsorption-photocatalytic degradation of hydrophobic pollutant under solar irradiation. Chem Eng J. 2015;262:1022-1032.

24. Zatloukalová K, Obalová L, Koči K, Čapek L, Matěj Z, Šnajdhaufová H, et al. Photocatalytic degradation of endocrine disruptor compounds in water over immobilized $\mathrm{TiO}_{2}$ photocatalysts Iranian J Chem Chemi Eng. 2017;36(2):29-38.

25. Mboula VM, Héquet V, Andres Y, Gru Y, Colin R, Doña-Rodríguez J, et al. Photocatalytic degradation of estradiol under simulated solar light and assessment of estrogenic activity. Appl Catalys B Environ. 2015;162:437-444.

26. Yang Y, Luo L, Xiao M, Li H, Pan X, Jiang F. One-step hydrothermal synthesis of surface fluorinated $\mathrm{TiO}_{2}$ /reduced graphene oxide nanocomposites for photocatalytic degradation of estrogens. Mater Sci Semicond Process. 2015;40:183-193.

27. Liu H, Neal AT, Zhu Z, Luo Z, Xu X, Tománek D, et al. Phosphorene: an unexplored 2D semiconductor with a high hole mobility. ACS nano. 2014;8(4):4033-4041.

28. Lee HU, Lee SC, Won J, Son BC, Choi S, Kim Y, et al. Stable semiconductor black phosphorus (BP)@titanium dioxide $\left(\mathrm{TiO}_{2}\right)$ hybrid photocatalysts. Sci Rep. 2015;5:8691. 
29. León A, Reuquen P, Garín C, Segura R, Vargas P, Zapata P, et al. FTIR and Raman characterization of $\mathrm{TiO}_{2}$ nanoparticles coated with polyethylene glycol as carrier for 2-methoxyestradiol. Appl Sci. 2017;7(1):49.

30. Nawaz M, Miran W, Jang J, Lee DS. One-step hydrothermal synthesis of porous 3D reduced graphene oxide/ $/ \mathrm{TiO}_{2}$ aerogel for carbamazepine photodegradation in aqueous solution. Appl Catalys $\mathrm{B}$ Environ. 2017;203:85-95.

31. Li L, Long Y, Chen $Y$, Wang S, Wang L, Zhang S, et al. Facile synthesis of $\mathrm{Fe} / \mathrm{Bi}_{2} \mathrm{SiO}_{5}$ nanocomposite with enhanced photocatalytic activity for degradation of $17 \beta$-Estradiol (E2). Solid State Sci. 2018;83:143-151.

32. Fernández L. Impact of operating conditions on the removal of endocrine disrupting chemicals by membrane photocatalytic reactor. Environ Technol. 2014;35(16):2068-2074.

33. Vijayabalan A, Selvam K, Velmurugan R, Swaminathan M. Photocatalytic activity of surface fluorinated $\mathrm{TiO}_{2}-\mathrm{P} 25$ in the degradation of Reactive Orange 4. J Hazard Mater. 2009;172(2-3): 914921.

34. Rahman MZ, Kwong CW, Davey K, Qiao SZ. 2D phosphorene as a water splitting photocatalyst: fundamentals to applications. Energy Environ Sci. 2016;9(3):709-728.

35. Alvarez-Corena JR, Bergendahl JA, Hart FL. Advanced oxidation of five contaminants in water by $\mathrm{UV} / \mathrm{TiO}_{2}$ : reaction kinetics and byproducts identification. J Environ Manag. 2016;181:544-551.

36. Ulhaq ZS, Kishida M. Brain aromatase modulates serotonergic neuron by regulating serotonin levels in zebrafish embryos and larvae. Front Endocrinol. 2018;9:230.

37. Lee $\mathrm{DH}$, Jo YJ, Eom HJ. Nonylphenol induces mortality and reduces hatching rate through increase of oxidative stress and dysfunction of antioxidant defense system in marine medaka embryo. Molecu Cell Toxicol. 2018;14(4):437-444.

38. Ren X, Lu F, Cui Y, Wang X, Bai C, Chen J, et al. Protective effects of genistein and estradiol on PAHsinduced developmental toxicity in zebrafish embryos. Hum Exp Toxicol, 2012;31(11):1161-1169.

39. Padilha J, Fazzio A, Silva AJ. Van der Waals heterostructure of phosphorene and graphene: tuning the Schottky barrier and doping by electrostatic gating. Phys Rev Lett. 2015;114(6): 066803.

40. Hu W, Wang T, Yang J. Tunable Schottky contacts in hybrid graphene-phosphorene nanocomposites. J Mater Chemis C. 2015;3(18):4756-4761.

\section{Figures}



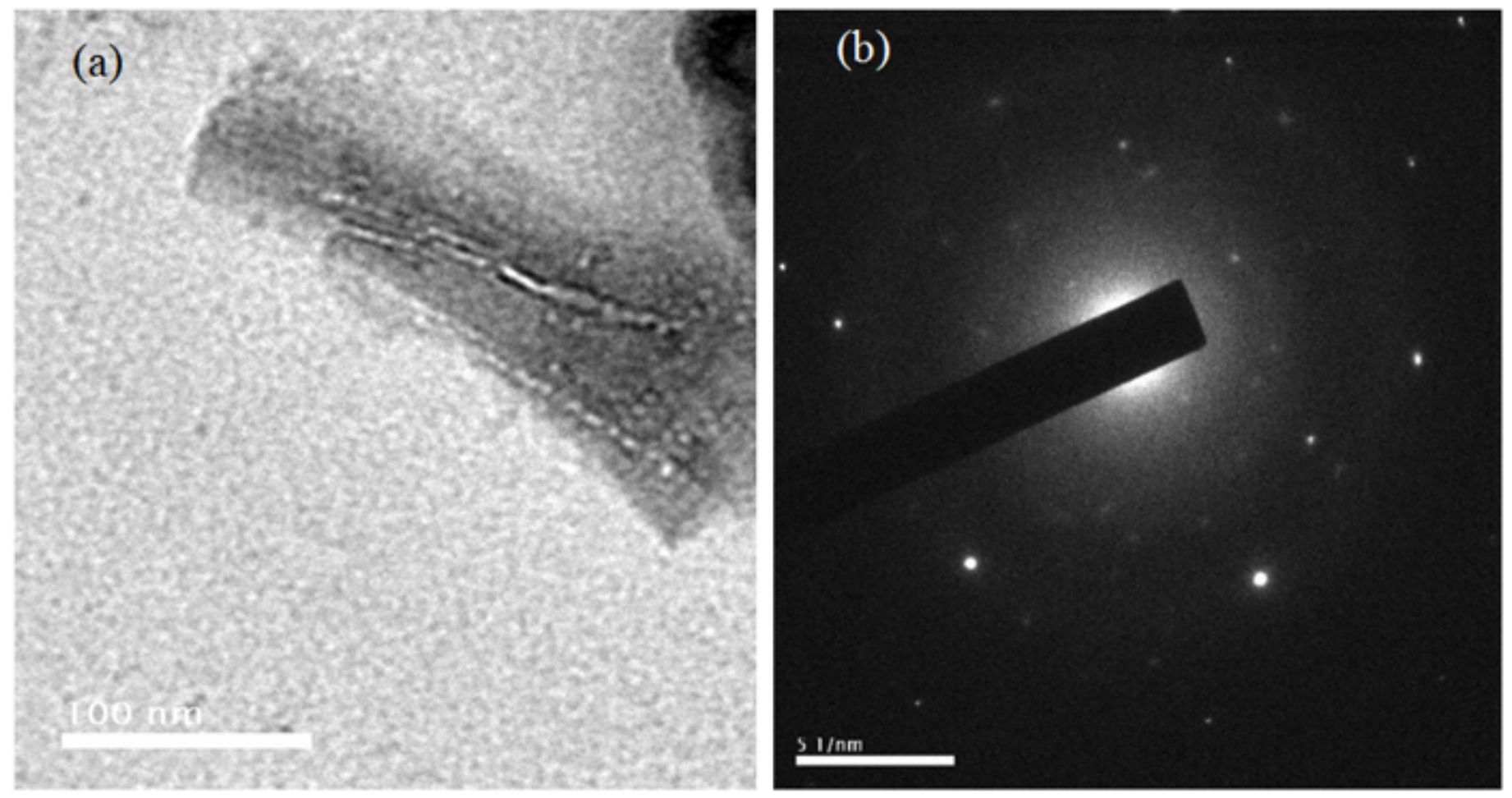

Figure 1

(a) TEM image and (b) electron diffraction pattern of PN
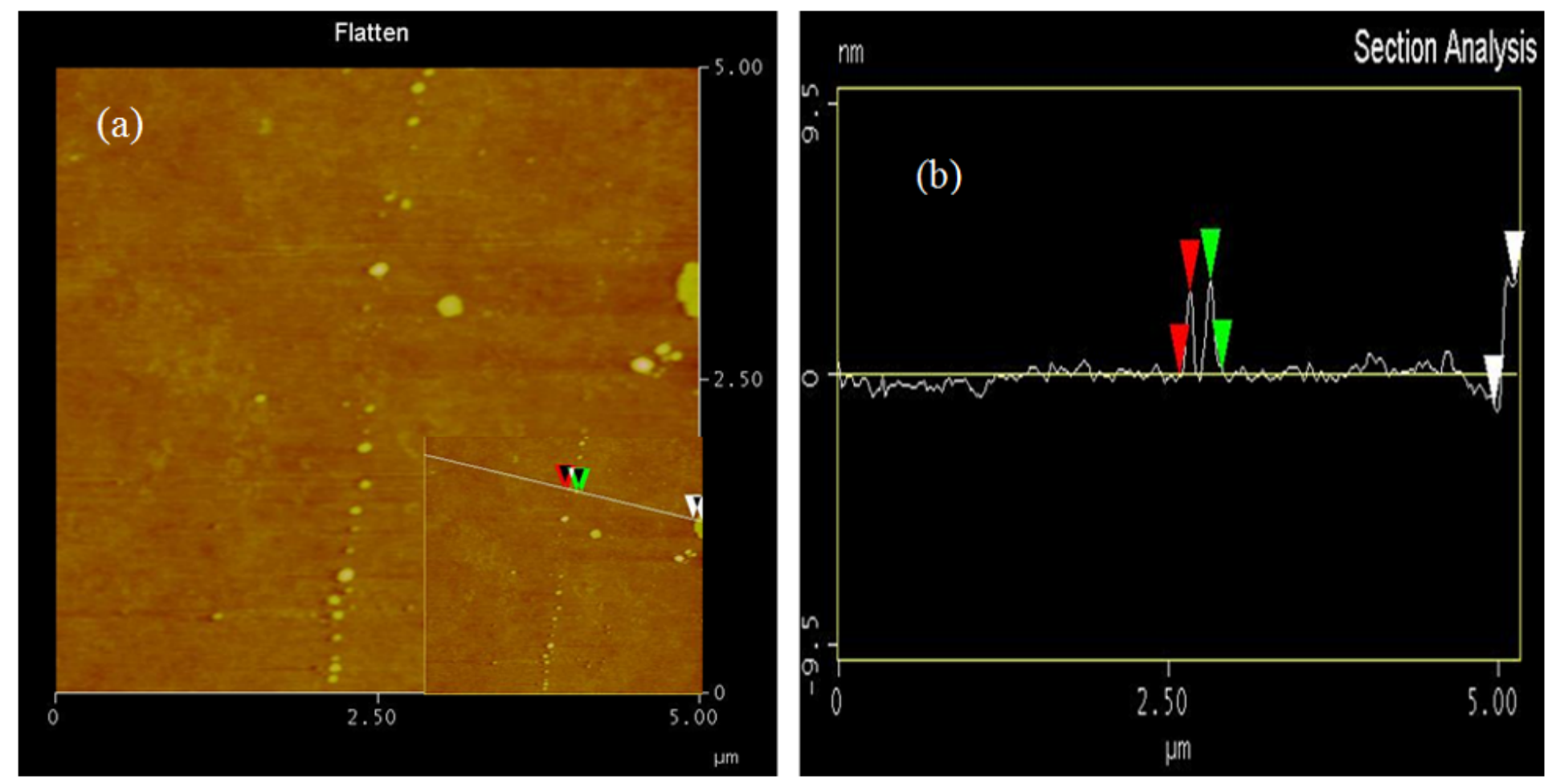

\section{Figure 2}

AFM spectra of composite (a) external surface morphology and (b) height profile 


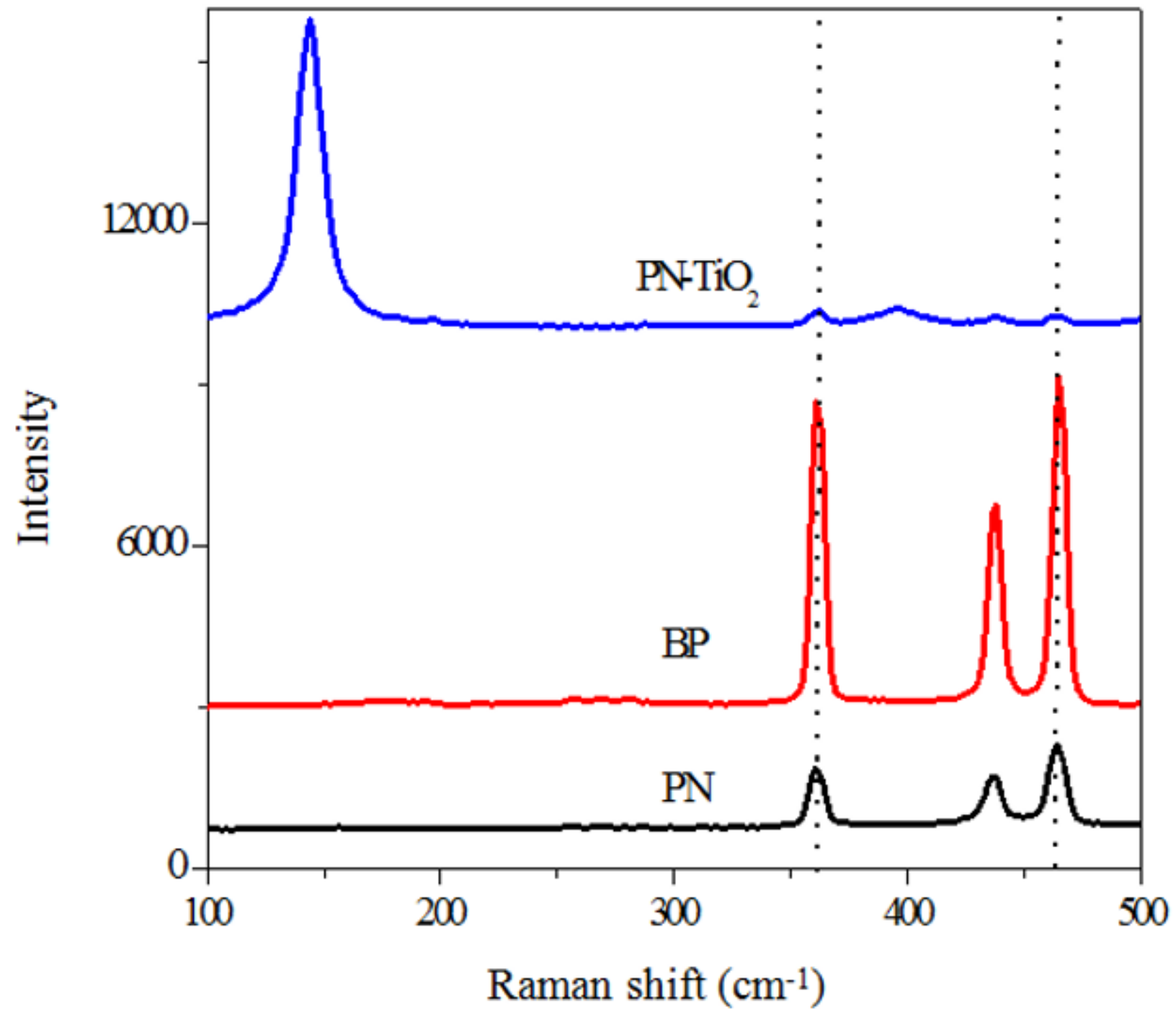

Figure 3

Raman spectra of BP, PN and PN-TiO2 

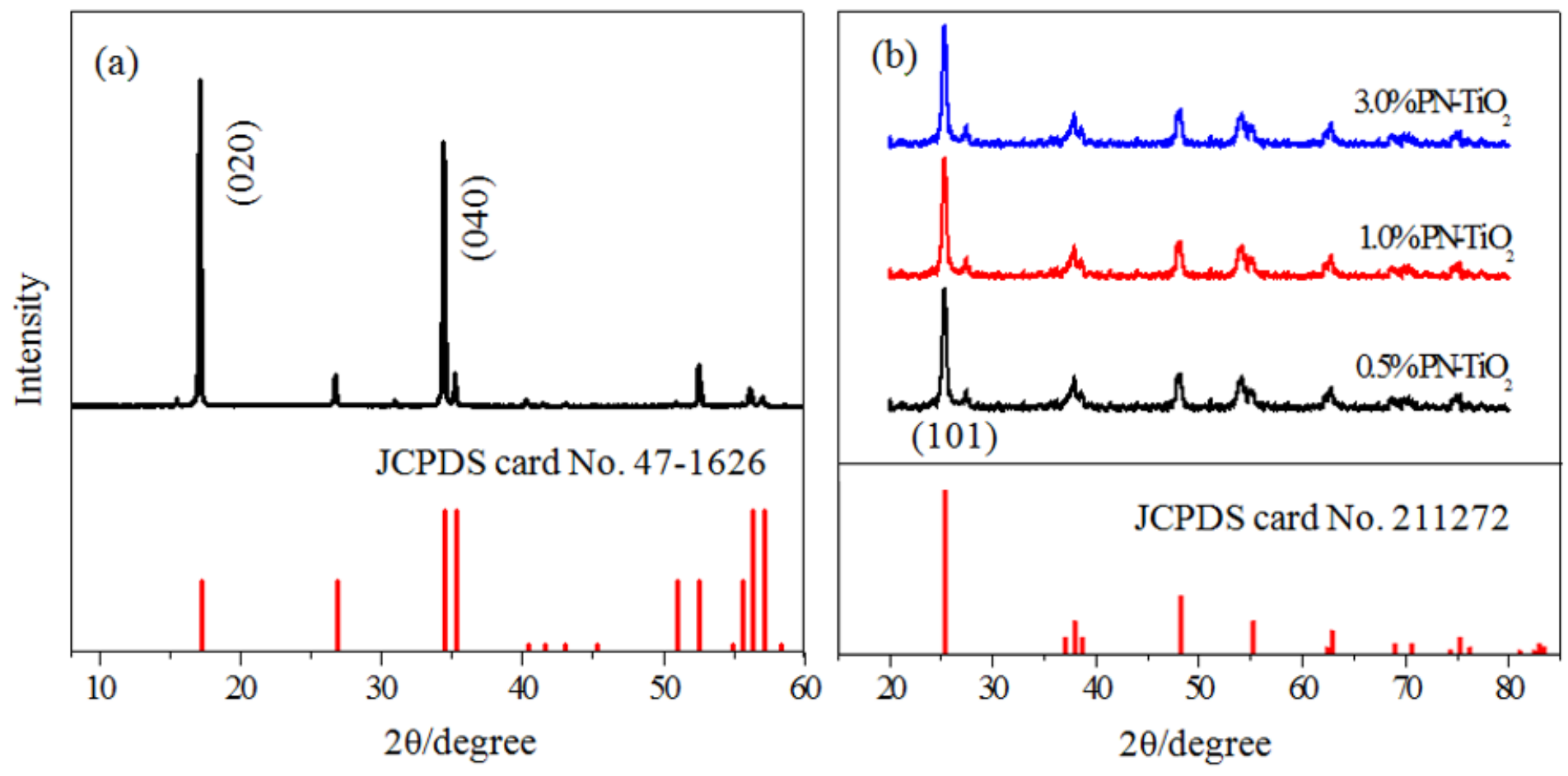

Figure 4

XRD pattern of (a) PN and (b) PN-TiO2

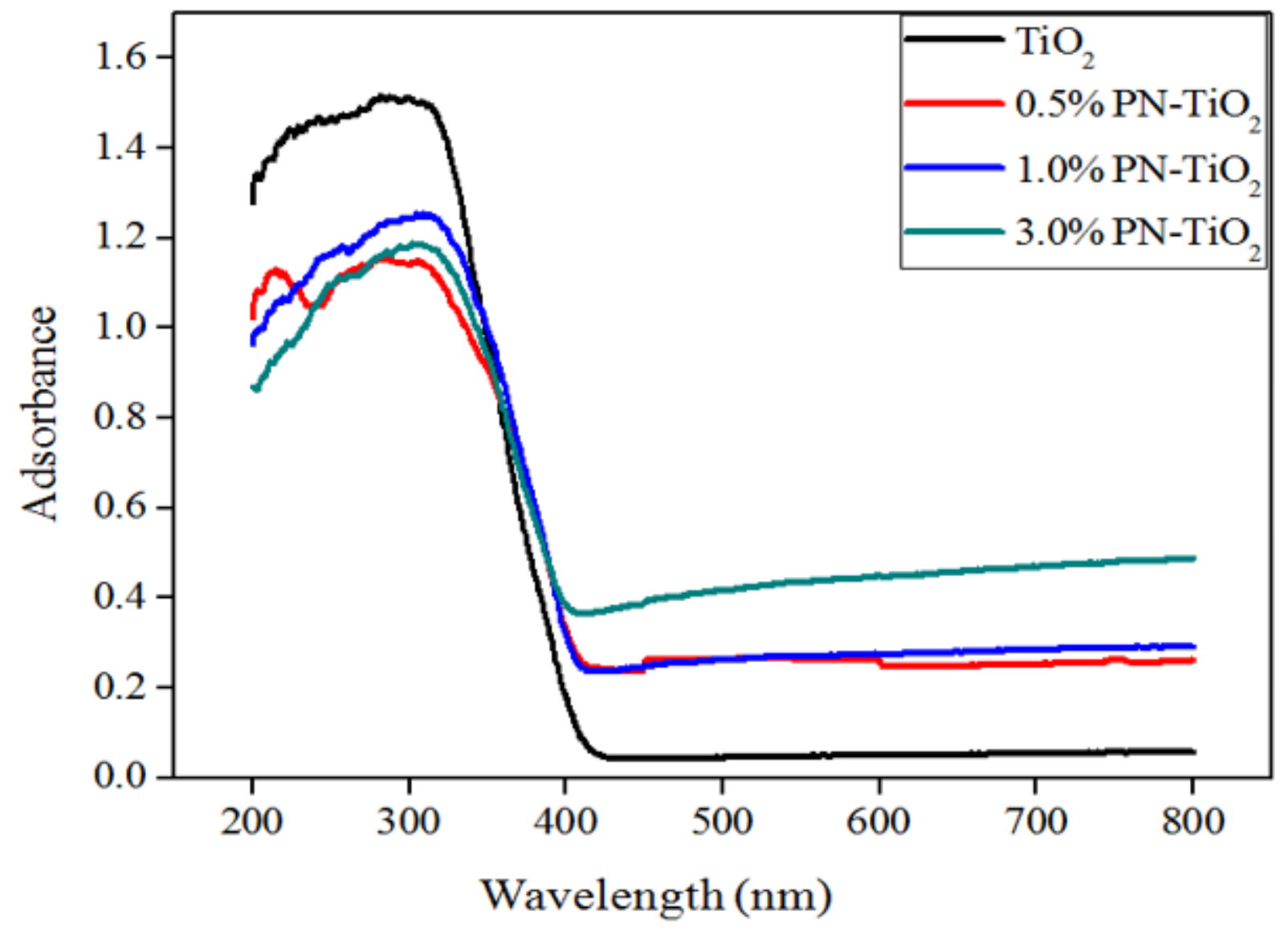

Figure 5 
UV-Vis absorption spectra of PN-TiO2 with various PN content
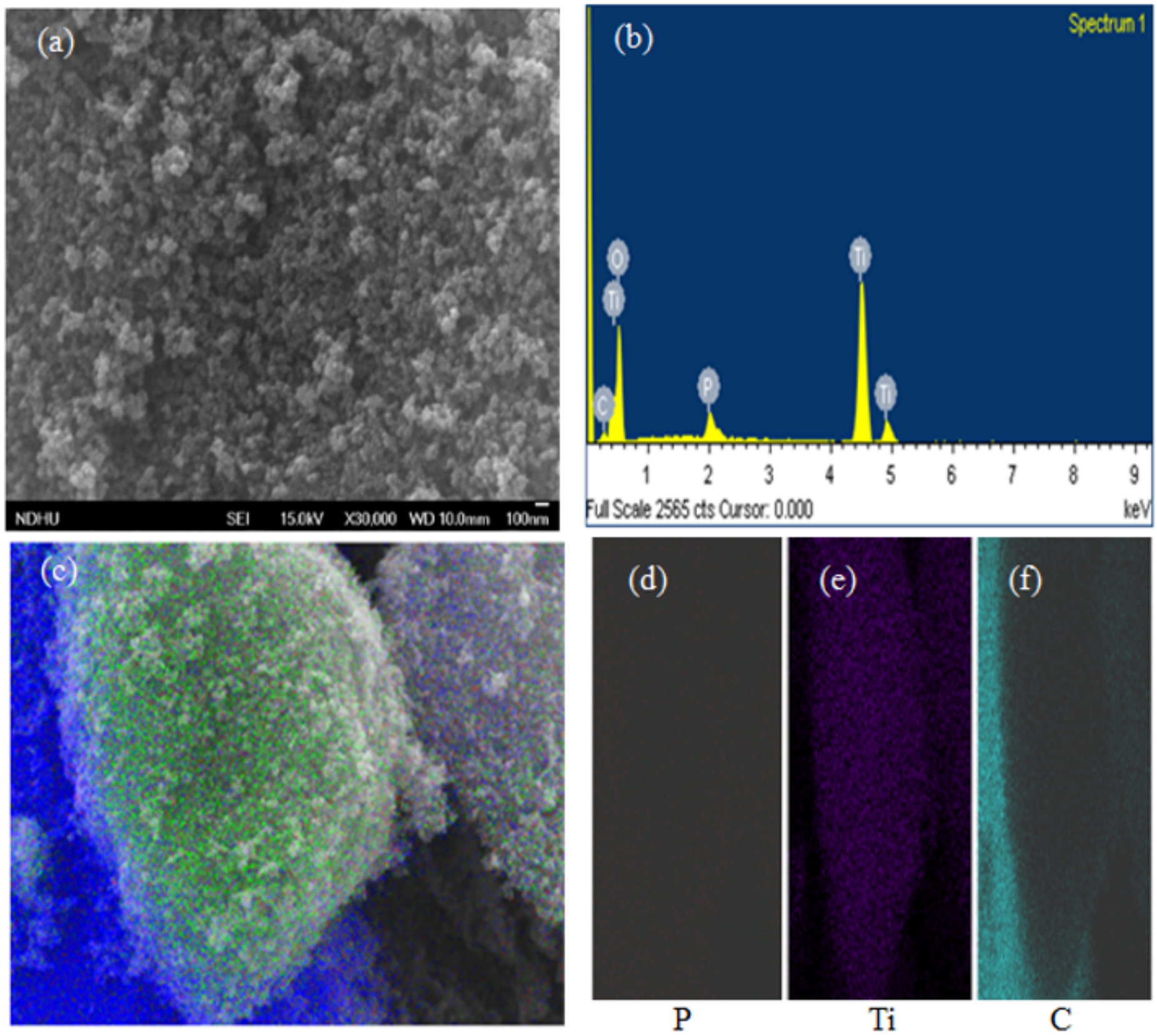

\section{Figure 6}

FE-SEM images: (a) SEM spectrum, (b) EDS of PN-TiO2 composite, (c) overlapping of $\mathrm{P}, \mathrm{Ti}$, and C elements, (d-f) elemental maps of $3 \% \mathrm{PN}-\mathrm{TiO} 2$ 


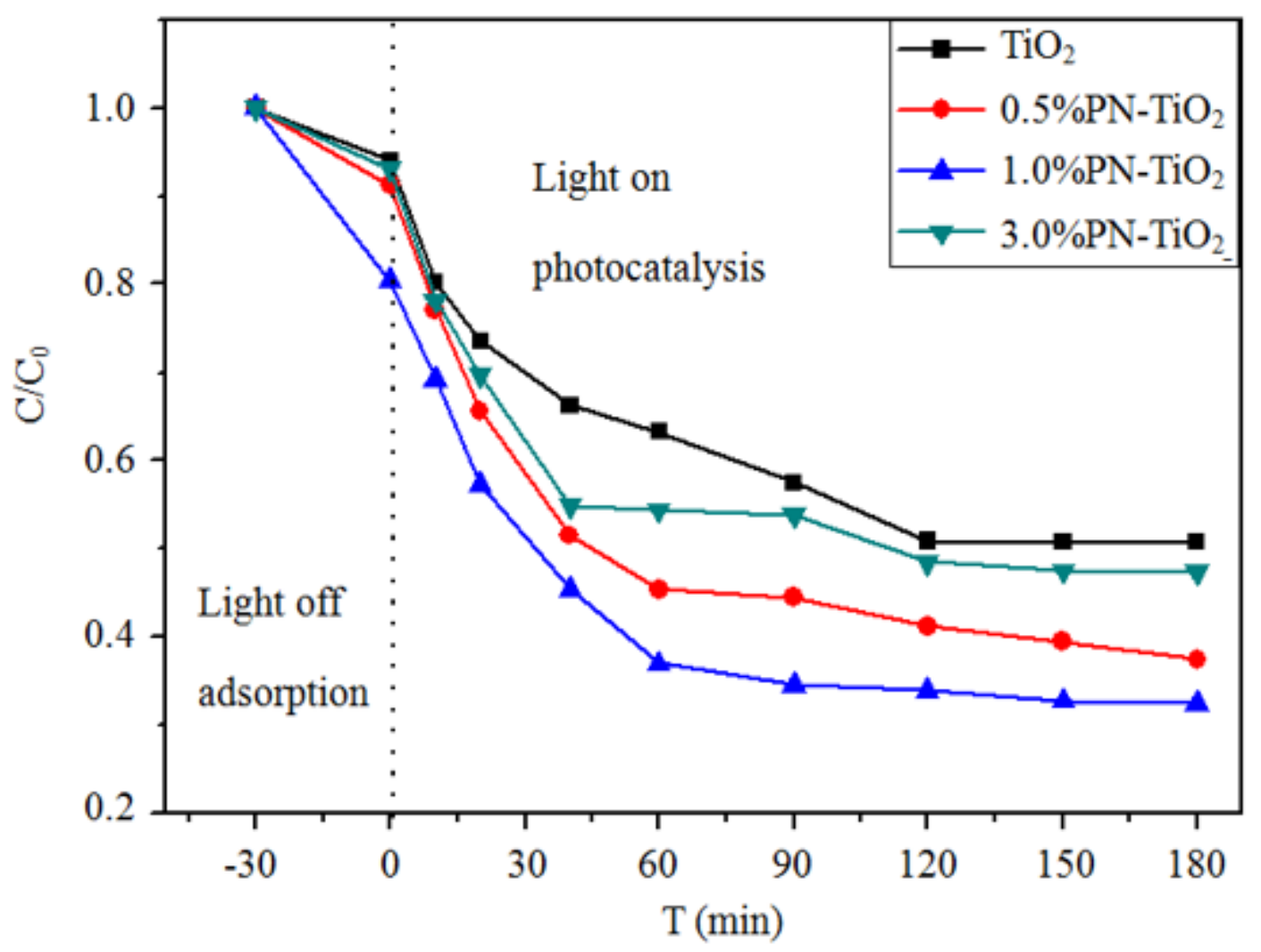

Figure 7

Photodegradation efficiency of different PN-TiO2composites 

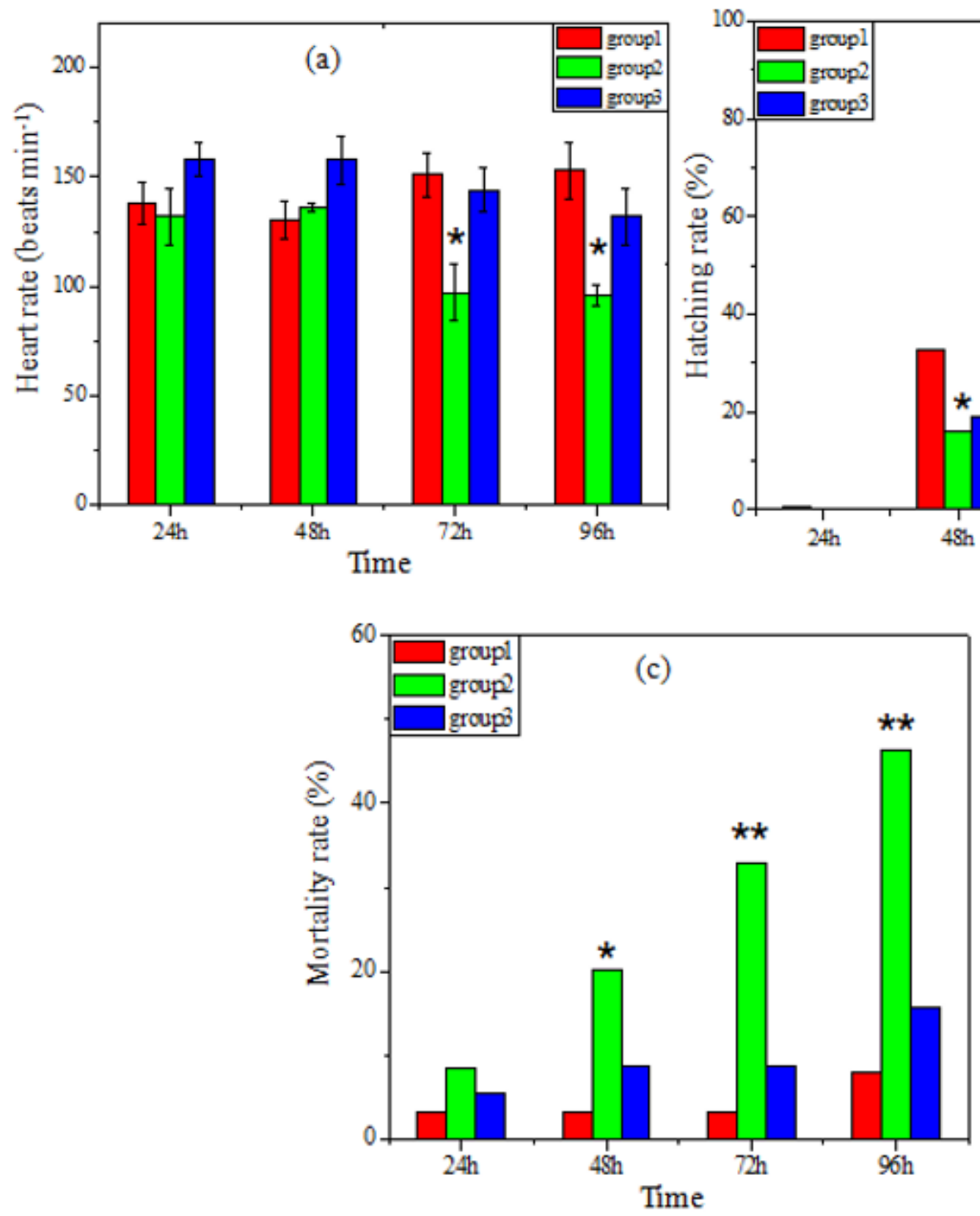

Figure 8

The heart rate (a), hatching rate (b) and mortality rate (c) of zebrafish embryos in three groups 